\title{
Hydrophilic and Hydrophobic Compounds Antithetically Affect the Growth of Eicosapentaenoic Acid-Synthesizing Escherichia coli Recombinants
}

\author{
Ryuji Hori ${ }^{\text {a,\# }}$, Takanori Nishida ${ }^{\text {b,\#, }}$ and Hidetoshi Okuyama ${ }^{\text {a,b,* }}$ \\ ${ }^{a}$ Course in Environmental Molecular Biology and Microbial Ecology, Division of Biosphere Science, Graduate School \\ of Environmental Science, Hokkaido University, Kita-ku, Sapporo 060-0810, Japan \\ ${ }^{b}$ Laboratory of Environmental Molecular Biology, Faculty of Environmental Earth Science, Hokkaido University, \\ Kita-ku, Sapporo 060-0810, Japan
}

\begin{abstract}
The growth of Escherichia coli DH5 $\alpha$ recombinants producing eicosapentaenoic acid (EPA) (DH5 $\alpha$ EPA +$)$ and those not producing EPA (DH5 $\alpha$ EPA-) was compared in the presence of hydrophilic or hydrophobic growth inhibitors. The minimal inhibitory concentrations of hydrophilic inhibitors such as reactive oxygen species and antibiotics were higher for DH5 $\alpha \mathrm{EPA}+$ than for DH5 $\alpha \mathrm{EPA}-$, and vice versa for hydrophobic inhibitors such as protonophores and radical generators. E. coli $\mathrm{DH} 5 \alpha$ with higher levels of EPA became more resistant to ethanol. The cell surface hydrophobicity of DH5 $\alpha$ EPA+ was higher than that of DH5 $\alpha$ EPA-, suggesting that EPA may operate as a structural constituent in the cell membrane to affect the entry and efflux of hydrophilic and hydrophobic inhibitors.
\end{abstract}

Keywords: Cell hydrophobicity, eicosapentaenoic acid, membrane-shielding effect, minimal inhibitory concentration, organic solvent.

\section{INTRODUCTION}

The cell membrane-shielding effect of long-chain polyunsaturated fatty acids (LC-PUFAs), such as eicosapentaenoic acid (EPA) and docosahexaenoic acid (DHA), in bacteria is thought to occur because a more hydrophobic interface is formed between the bilayers of cell membrane phospholipids acylated with a LC-PUFA in combination with a medium-chain saturated or mono-unsaturated fatty acid, and this interface shields the entry of hydrophilic compounds [1, 2]. We showed that Escherichia coli cells that had been transformed with EPA biosynthesis pfa genes [3, 4], and naturally EPA-producing Shewanella marinintestina IK1 (IK-1) have the potential to prevent the entry of $\mathrm{H}_{2} \mathrm{O}_{2}$ molecules through the cell membrane [1]. When these bacterial cells producing EPA were treated with $\mathrm{H}_{2} \mathrm{O}_{2}$, intracellular concentrations of $\mathrm{H}_{2} \mathrm{O}_{2}$ in these cells were maintained at levels lower than those in their reference cells producing no EPA $[1,4]$. Thus, the generation of protein carbonyls was suppressed to a lesser extent in cells with EPA than in cells without EPA. This has been regarded as a novel antioxidative function of PUFAs such as EPA and DHA.

In a previous study [5], we used IK-1 and its EPAdeficient mutant IK-1 $\Delta 8$ (IK-1 $\Delta 8$ ) to show that membrane

\footnotetext{
*Address correspondence to this author at Hokkaido University, Faculty of Environmental Earth Science, Hokkaido University, Kita-ku, Sapporo 0600810, Japan; Tel: +81-11-706-4523; Fax: +81-11-706-4523;

E-mail: hoku@ees.hokudai.ac.jp

"These authors contributed equally to this work.

${ }^{\S}$ Present address: Akita Research Institute for Food and Brewing (ARIF), Araya-machi, Akita, Japan
}

EPA is involved in the increased hydrophobicity of bacterial cells and that it affects the entry of hydrophilic and hydrophobic compounds. Briefly, IK- 1 and IK- $1 \Delta 8$ were grown on microtiter plates at $20{ }^{\circ} \mathrm{C}$ in nutrient media that contained various types of growth inhibitors. The minimal inhibitory concentrations (MICs) of water-soluble $\mathrm{H}_{2} \mathrm{O}_{2}$, tert-butyl hydroxyl peroxide (tert-BHP) and antibiotics were higher for IK-1 than for IK-1 $\Delta 8$. In contrast, IK-1 was less resistant than IK- $1 \Delta 8$ to two hydrophobic oxidative phosphorylation uncouplers, carbonyl cyanide $m$-chloro phenyl hydrazone (CCCP) and $N, N^{\prime}$-dicyclohexylcarbodiimide. The hydrophobicity of the IK-1 and IK-1 $\Delta 8$ cells determined using the bacterial adhesion to hydrocarbon method [6] was higher for IK-1 cells, which contained EPA at approximately $10 \%$ of total fatty acids, compared with their counterparts with no EPA. From these results, we concluded that the high hydrophobicity of IK-1 cells can be attributed to the presence of membrane EPA, which shields the entry of hydrophilic membrane-diffusible compounds, and that hydrophobic compounds such as CCCP and $N, N^{\prime}$-dicyclohexylcarbodiimide diffuse more effectively in the membranes of IK1 , where these hydrophobic compounds can exhibit their inhibitory activities, than in the membranes of IK- $1 \Delta 8$. However, the membrane-shielding functions of LC-PUFAs have not been reported for bacteria other than IK-1 and $E$. coli recombinants producing EPA or DHA.

In this study, we used EPA-producing and EPA-not producing $E$. coli $\mathrm{DH} 5 \alpha$ recombinants to further investigate the applicability of the membrane-shielding effects of EPA against various kinds of hydrophilic and hydrophobic growth inhibitors, such as reactive oxygen species $\left(\mathrm{H}_{2} \mathrm{O}_{2}\right.$ and tertBHP), hydrophilic and hydrophobic radical generators $\left(2,2^{\prime}-\right.$ 
azobis-(2-amidopropane)hydrochloride (AAPH) and 2,2'azobis-(2,4-dimethyl)valeronitrile (AMVN), respectively), hydrophilic antibiotics (ampicillin sodium, kanamycin sulfate and streptomycin sulfate), an uncoupling reagent in oxidative phosphorylation (CCCP) and organic solvent (ethanol). To evaluate the relation between hydrophobicity of each bacterial cell and the cellular content of EPA, we used the bacterial adhesion to hydrocarbon method $[5,6]$ and tested E. coli recombinants with various levels of EPA.

The E. coli strain DH5 $\alpha$ was used as host. Recombinant cells of $E$. coli DH5 $\alpha$ (see below) were cultivated normally at $20^{\circ} \mathrm{C}$ in Luria-Bertani (LB) medium with shaking at 150 $\mathrm{rpm}$ in the presence of $50 \mu \mathrm{g} / \mathrm{ml}$ ampicillin and $30 \mu \mathrm{g} / \mathrm{ml}$ chloramphenicol for two days. Bacterial strains and vectors used in this study are listed in Table $\mathbf{1 .}$

Unless otherwise stated, E. coli $\mathrm{DH} 5 \alpha$ was transformed with pEPA $\Delta 1,2,3$, which is a cosmid clone that includes four $(p f a A, p f a B, p f a C$ and $p f a D)$ of the five genes essential for the biosynthesis of EPA and an additional two open reading frames unnecessary for EPA biosynthesis from Shewanella pneumatophori SCRC-2738 and a pSTV28 plasmid vector carrying $p f a E$ encoding phosphopantetheinyl transferase (pSTV::pfaE); $p f a E$ is the fifth gene needed for EPA biosynthesis from the same bacterium ([7] and Table 1). The host E. coli DH5 $\alpha$ cells that had been transformed with these two vectors produced EPA at a level of $10 \%$ of total fatty acids, when growth at $20{ }^{\circ} \mathrm{C}$ [3]. The E. coli $\mathrm{DH} 5 \alpha$ recombinant reference strain, which has no ability to produce EPA, was transformed with pEPA $\Delta 1,2,3$ and empty pSTV28. E. coli DH $5 \alpha$ with and without EPA were designated DH5 $\alpha$ EPA+ and $\mathrm{DH} 5 \alpha \mathrm{EPA}-$, respectively. To increase the content of EPA, E. coli DH5 $\alpha$ was transformed with pEPA $\Delta 1,3,4,9$, which is a pNEB clone containing $p f a A, p f a B, p f a C, p f a D$ and $p f a E$ but no unnecessary open reading frames from S. pneumatophori SCRC-2738 [8]. Levels of EPA of this recombinant, which was grown at $20{ }^{\circ} \mathrm{C}$, were approximately $20 \%$ of total fatty acids [9].
To perform growth inhibition tests, 96-well microtiter plates (0.35 ml per well; Iwaki, Tokyo, Japan) were used, as described previously [5]. Briefly, E. coli DH5 $\alpha$ recombinant cells were grown for $48 \mathrm{~h}$ at $20{ }^{\circ} \mathrm{C}$. One hundred microliters of these cultures $\left[1.0\right.$ at $\left.600 \mathrm{~nm}\left(\mathrm{OD}_{600}\right)\right]$ was diluted with $100 \mathrm{ml}$ of medium. To $180 \mu \mathrm{l}$ of the diluted cultures, $20 \mu \mathrm{l}$ of aqueous solutions containing various concentrations of growth inhibitors were added. AAPH and AMVN were used as hydrophilic and hydrophobic radical generators, respectively. CCCP was used as a hydrophobic proton conductor. To dissolve AMVN and CCCP, absolute ethanol was used. For AMVN and CCCP, $2 \mu$ l aliquots were mixed with $198 \mu \mathrm{l}$ of the diluted cultures. After inoculation, the plates were incubated for four days at $20{ }^{\circ} \mathrm{C}$. Growth of cells was monitored visually and the bottom face of the microtiter plates was scanned with a scanner.

To cultivate E. coli recombinants in LB medium containing ethanol, test tubes with silicon caps were used to prevent organic solvent from volatizing. The $\mathrm{OD}_{600}$ of $E$. coli $\mathrm{DH} 5 \alpha \mathrm{EPA}+$ and $E$. coli $\mathrm{DH} 5 \alpha \mathrm{EPA}-$ cells precultivated in LB medium, as described above, was adjusted to 1.0 with the same medium. One hundred microliter aliquots of the precultures were mixed with $100 \mathrm{ml}$ of the medium. Ten milliliters of the cultures were transferred to test tubes. To these cultures, ethanol $(0,300,500,600$, and $700 \mu 1)$ was added and then they were cultivated with shaking at $150 \mathrm{rpm}$ at $20{ }^{\circ} \mathrm{C}$. It is known that a strain of $E$. coli grows weekly in ethanol concentrations above $6 \%$ by volume [10].

The hydrophobicities of cells of DH5 $\alpha$ EPA+ and DH $5 \alpha E P A$ - were estimated by the bacterial adhesion to hydro-carbon method [6], as described previously [5]. The hydrophobicity was expressed as a percentage of the adherence of cells to hexadecane and calculated as $100 \times\left(\mathrm{OD}_{600}\right.$ of the aqueous phase after vortex/OD 600 of the initial cell suspension).

Table 1. Strains and Vectors Used in this Study

\begin{tabular}{|c|c|c|}
\hline Strain/Plasmid/Cosmid & Relevant Characteristics & Source \\
\hline \multicolumn{3}{|l|}{ Strain } \\
\hline Escherichia coli $\mathrm{DH} 5 \alpha$ & $\begin{array}{l}\text { deo } \mathrm{R}, \text { end } \mathrm{A} 1, \text { gyrA96, hsd } \mathrm{R} 17\left(\mathrm{rK}^{-} \mathrm{mK}^{+}\right), \text {recA1 phoA, relA1, thi-1, } \Delta(\text { lac ZYA-argF }) \\
\mathrm{U} 169 \phi 80 \mathrm{~d} l a c \mathrm{Z} \Delta \mathrm{M} 15, \mathrm{~F}^{-}, \lambda^{-}, \text {sup } 44\end{array}$ & 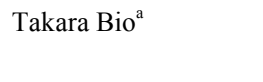 \\
\hline \multicolumn{3}{|l|}{ Plasmid/Cosmid ${ }^{\mathrm{b}}$} \\
\hline pSTV28 & Low-copy-number cloning vector, $\mathrm{Cm}^{\mathrm{r}}$ & Takara Bio \\
\hline pSTV::pfaE & pSTV28 carrying pfaE from $S$. pneumatophoruse SCRC-2738 & {$[7]$} \\
\hline pNEB139 & High-copy-number expression vector, $\mathrm{Amp}^{\mathrm{r}}$ & New England Biolabs ${ }^{c}$ \\
\hline $\operatorname{pEPA} \Delta 1,3,4,9$ & pNEB carrying $p f a A-E$ from $S$. pneumatophori SCRC-2738 & \\
\hline & & Stratagene $^{\mathrm{d}}$ \\
\hline pWE15 & Cosmid expression vector, $\mathrm{Km}^{\mathrm{r}}, \mathrm{Amp}^{\mathrm{r}}$ & Takara Bio \\
\hline $\mathrm{pEPA} \Delta 1,2,3$ & pWE15 carrying an EPA gene cluster that lacks $p f a E$ from $S$. pneumatophori SCRC-2738 & \\
\hline
\end{tabular}

${ }^{\text {a }}$ Takara Bio Inc., Tokyo, Japan

${ }^{\mathrm{b}}$ Abbreviations of antibiotics: Km, kanamycin; Amp, ampicillin; and $\mathrm{Cm}$, chloramphenicol.

${ }^{c}$ New England Biolabs, Ipswich, MA, USA.

${ }^{\mathrm{d}}$ Stratagene, La Jolla, CA, USA. 
Fatty acids of cells were analyzed as methyl esters by gas-liquid chromatography, as previously described [7].

The MICs of $\mathrm{H}_{2} \mathrm{O}_{2}$ and tert-BHP were both $100 \mu \mathrm{M}$ for DH $5 \alpha E P A+$ and were both $10 \mu \mathrm{M}$ for DH5 $\alpha E P A-$ (Fig. 1A). The MICs of AAPH and AMVN were $10 \mu \mathrm{M}$ and 1 $\mu \mathrm{M}$, respectively, for DH5 $\alpha \mathrm{EPA}+$ and were $1 \mu \mathrm{M}$ and 10 $\mu \mathrm{M}$, respectively, for DH5 $\alpha E P A-$ (Fig. 1B). The MIC of CCCP was $1 \mathrm{mM}$ and $10 \mathrm{mM}$ for DH5 $\alpha E P A+$ and for $\mathrm{DH} 5 \alpha \mathrm{EPA}-$, respectively. AMVN and $\mathrm{CCCP}$ are waterinsoluble and ethanol-soluble compounds. The final concentration of ethanol in the culture medium was $1 \%(\mathrm{v} / \mathrm{v})$, and this concentration of ethanol had no effect on the growth of DH5 $\alpha$ EPA+ and DH5 $\alpha$ EPA-. DH5 $\alpha$ EPA+ was much more resistant to the three hydrophilic compounds, $\mathrm{H}_{2} \mathrm{O}_{2}$, tert-BHP and AAPH, than was DH5 $2 \mathrm{EPA}-$. The same tendency was observed, when cells of DH5 $\alpha$ EPA+ and DH5 $\alpha$ EPAwere treated with three types of water-soluble antibiotics including ampicillin sodium, kanamycin sulfate and streptomycin sulfate. However, DH5 $\alpha \mathrm{EPA}+$ was more sensitive to the hydrophobic AMVN and CCCP than was DH5 $\alpha$ EPA-. The results are summarized in Table 2.

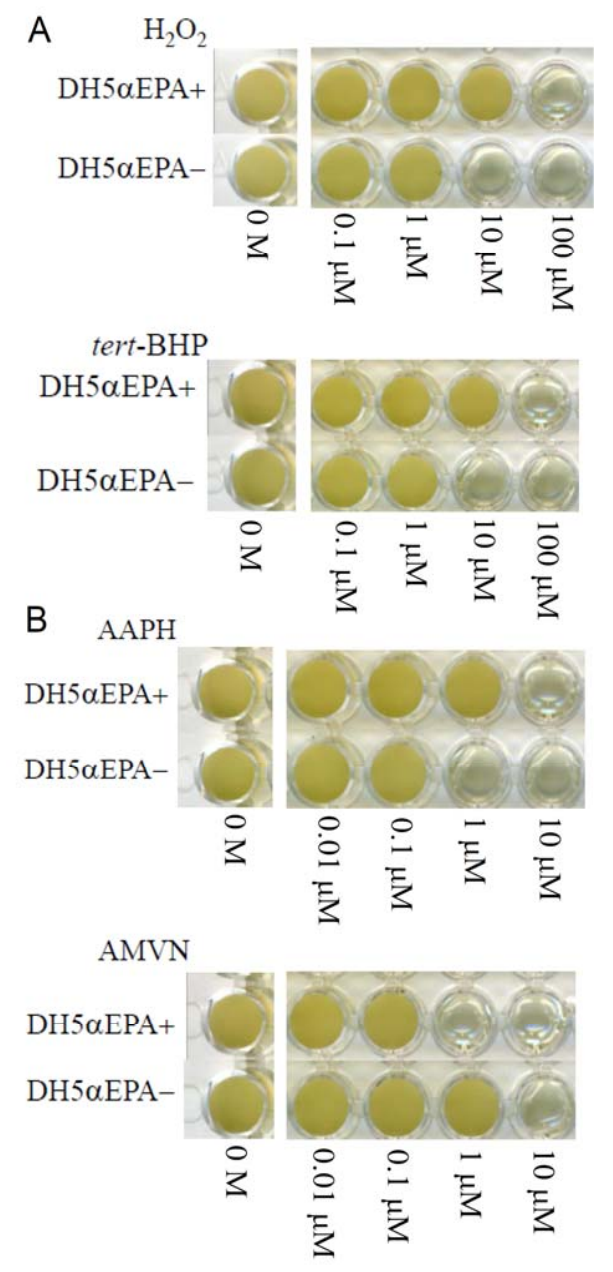

Fig. (1) Effects of concentration of various compounds on the growth of $E$. coli DH5 $\alpha$ with EPA (DH5 $\alpha$ EPA+) and that with no EPA (DH5 $\alpha$ EPA-). (A) reactive oxygen species; (B) radical generators. $\mathrm{H}_{2} \mathrm{O}_{2}$, hydrogen peroxide; tert-BHP, tert-butyl hydroperoxide; AAPH, 2,2'-azobis-(2-amidopropane)hydrochloride; and AMVN, 2,2'-azobis-(2,4-dimethyl)valeronitrile. Cells were grown for 4 days at $20^{\circ} \mathrm{C}$.
DH5 $\alpha$ EPA+ and DH5 $\alpha$ EPA - cells were cultured in the presence and in the absence of ethanol at $20^{\circ} \mathrm{C}$. DH5 $\alpha$ EPA+ cells grew much better in approximately $5 \%$ ethanol than DH5 $\alpha E P A$ - for seven days at $20^{\circ} \mathrm{C}$ and the former weakly grew even in approximately $6 \%$ ethanol but the latter did not under the same conditions. No growth was observed in both strains in $7 \%$ ethanol. When $E$. coli DH5 $\alpha$ carrying pNEB $\Delta 1,3,4,9$ was grown at $20{ }^{\circ} \mathrm{C}$, cells grew well in approximately $5 \%$ and $6 \%$ ethanol than DH5 $\alpha$ EPA+ cells and did not grow in $7 \%$ ethanol (Table 3 ).

The bacterial cell surface hydrophobicity of various $E$. coli DH5 $\alpha$ recombinants was expressed as the percentage adhesion of bacterial cells to water measured using the bacterial adhesion to hydrocarbon method. To change the cellular level of EPA, E. coli DH5 $\alpha$ cells were transformed by different combinations of vectors carrying $p f a$ genes and grown at different temperatures. Levels of EPA of E. coli DH5 $\alpha$ cells that had been transformed with pEPA $\Delta 1,2,3$ plus pSTV28::pfaE were $16 \% \pm 1 \%, 11 \% \pm 1 \%$ and $0 \%$ of the total fatty acids at 15,20 and $30{ }^{\circ} \mathrm{C}$, respectively. The cells transformed with pEPA $\Delta 1,2,3$ plus pSTV28 had no EPA (Table 4). When E. coli $\mathrm{DH} 5 \alpha$ cells were transformed with pEPA $\Delta 1,3,4,9$ and grown at $20{ }^{\circ} \mathrm{C}$, the EPA level was $21 \% \pm 2 \%$. DHA5 $\alpha$ cells with higher levels of EPA had higher cell hydrophobicity (lower values; Table 4). The lowest hydrophobicity (highest value) was $98 \%$ for the two types of $E$. coli DH5 $\alpha$ cells with no EPA: those grown at 30 ${ }^{\circ} \mathrm{C}$ with pEPA $\Delta 1,2,3$ plus pSTV28::pfaE and those grown at $20{ }^{\circ} \mathrm{C}$ with pEPA $\Delta 1,2,3$ plus empty pSTV 28 .

The present results using E. coli recombinant cells producing EPA and those not producing EPA were almost the same as the results using a native EPA-producing strain $S$. marinintestina IK- 1 and its EPA-deficient mutant IK- $1 \Delta 8$ in terms of the resistance and sensitivity to hydrophilic and hydrophobic growth inhibitors [5]. Considering that the EPA content of DH $5 \alpha \mathrm{EPA}+$ (a recombinant carrying pEPA $\Delta 1,2,3$ plus pSTV::pfaE) is approximately $10 \%$ of total fatty acids, these results can also be explained by the hydrophobicity of the EPA-containing cell membranes. The converse results using hydrophobic compounds as substrate, such as AMVN and CCCP (Fig. 1B and Table 2), can be also explained by the increased cell surface hydrophobicity. AMVN and CCCP tend to accumulate in the more hydrophobic cell membrane of $\mathrm{DH} 5 \alpha \mathrm{EPA}+$, where more radicals are produced by AMVN and oxidative phosphorylation is inhibited more effectively by CCCP. Since hydrophilic antibiotics with molecular weights less than about 600 pass nonspecifically through porin channels on the outer membrane and not by diffusion [11], streptomycin sulfate, with a molecular weight of 1457.4, could be shielded at the outer and inner membranes, although we have not confirmed the distribution of EPA in both the membranes.

Higher levels of EPA in E. coli DH5 $\alpha$ recombinants cells provided higher hydrophobicity of the cells (Table 4). As the relieving effects of EPA on $\mathrm{H}_{2} \mathrm{O}_{2}$-induced growth inhibition increased with cellular levels of EPA [9], it is considered that higher MICs of various hydrophilic growth inhibitors would be obtained for cells with higher cell surface hydrophobicity and vice versa for cells with lower cell surface hydrophobicity. Therefore, the function of EPA in recombinant $E$. coli $\mathrm{DH} 5 \alpha$ cells would be based on the membrane- 
Table 2. Effects of Various Hydrophilic and Hydrophobic Compounds on the Growth of Cells of E. coli DH5 $\alpha$ Recombinants with EPA (DH5 $\alpha$ EPA+) and without EPA (DH5 $\alpha$ EPA-)

\begin{tabular}{|c|c|c|c|}
\hline & Solvent & DH5 $\alpha$ EPA+ & DH5 $\alpha$ EPA- \\
\hline \multicolumn{4}{|l|}{ Reactive oxygen species (MW) } \\
\hline $\mathrm{H}_{2} \mathrm{O}_{2}(34.0)$ & Water & $100 \mu \mathrm{M}$ & $10 \mu \mathrm{M}$ \\
\hline \multicolumn{4}{|l|}{ Radical generator } \\
\hline AAPH (271.19) & Water & $10 \mu \mathrm{M}$ & $1 \mu \mathrm{M}$ \\
\hline $\operatorname{AMVN}(248.37)$ & $1 \%$ Ethanol $^{\mathrm{b}}$ & $1 \mu \mathrm{M}$ & $10 \mu \mathrm{M}$ \\
\hline \multicolumn{4}{|l|}{ Antibiotics } \\
\hline Streptomycin sulfate (1457.4) & Water & $3 \mu \mathrm{g} / \mathrm{ml}$ & $0.3 \mu \mathrm{g} / \mathrm{ml}$ \\
\hline \multicolumn{4}{|c|}{ Oxidative phosphorylation uncouplers } \\
\hline CCCP (204.1) & $1 \%$ Ethanol & $1 \mathrm{mM}$ & $10 \mathrm{mM}$ \\
\hline
\end{tabular}

${ }^{a} \mathrm{MW}$, molecular weight; MICs, minimal inhibitory concentrations; AAPH, 2,2'-azobis-(2-amidopropane)hydrochloride; AMVN, 2,2'-azobis-(2,4-dimethyl)valeronitrile tert-BHP, tert-butyl hydroxyl peroxide; CCCP, carbonyl cyanide $m$-chloro phenyl hydrazone.

${ }^{\mathrm{b}}$ Final concentration.

Table 3. Effects of Various Concentrations of Ethanol on the Growth of Cells of E. coli DH5 $\alpha$ Recombinants Producing Various Levels of EPA

\begin{tabular}{|c|c|c|c|c|c|}
\hline & \multicolumn{5}{|c|}{ OD $_{600}$ of Cultures Containing Ethanol at Approximately ${ }^{\mathrm{a}}$} \\
\hline & $0 \%$ & $3 \%$ & $5 \%$ & $6 \%$ & $7 \%$ \\
\hline \multicolumn{6}{|l|}{ E. coli $\mathrm{DH} 5 \alpha$ cells $^{\mathrm{b}}$ carrying } \\
\hline $\mathrm{pEPA} \Delta 1,3,4,9$ & $3.4 \pm 0.1$ & $3.1 \pm 0.4$ & $1.5 \pm 0.1$ & $0.03 \pm 0.01$ & $\mathrm{NG}^{\mathrm{c}}$ \\
\hline pEPA $\Delta 1,2,3+$ pSTV $:: p f a E^{\mathrm{d}}$ & $3.4 \pm 0.2$ & $2.9 \pm 0.4$ & $1.0 \pm 0.1$ & $0.01 \pm 0.00$ & NG \\
\hline pEPA $\Delta 1,2,3+$ pSTV $^{d}$ & $3.2 \pm 0.2$ & $2.8 \pm 0.4$ & $0.4 \pm 0.1$ & NG & NG \\
\hline
\end{tabular}

${ }^{a}$ Values are average \pm standard deviation of three independent measurements.

${ }^{\mathrm{b}}$ Cells were grown for 7 days at $20^{\circ} \mathrm{C}$.

${ }^{\mathrm{c}}$ No growth detected.

${ }^{\mathrm{d}} \mathrm{pEPA} \Delta 1,2,3+$ pSTV::pfaE and pEPA $\Delta 1,2,3+$ pSTV are DH5 $\alpha E P A+$ and DH5 $\alpha$ EPA-, respectively.

shielding effects of EPA against hydrophilic compounds and this function of EPA would not apply to hydrophobic compounds, which tend to accumulate in the membranes. In addition to these physical effects of EPA, EPA may have specific interactions with proteins involved in membrane transport, such as Omp, TolC and Acr proteins [5].

E. coli $\mathrm{DH} 5 \alpha \mathrm{EPA}+$ grew in the presence of higher concentrations of ethanol, compared to E. coli DH5 $\alpha$ EPA(Table 3). In general, the organic solvent tolerance of $E$. coli arises mainly from the AcrAB-TolC and AcrEF-TolC efflux pumps [11]. The finding that the lack of EPA leads to the decreased concentrations of a tentative TolC family protein and decreased growth rates in the EPA-deficient mutant of
Shewanella livingstonensis Ac10 [12] supports the involvement of TolC protein in the increased efflux activity of organic solvents in DH5 $2 \mathrm{EPA}+$. However, the relationship between EPA and Acr proteins has not been elucidated. Ethanol is only slightly less polar than water and is freely permeable across bacterial membranes [10] and affects, in addition to proteins on the cell surface and within the membranes, cytoplasmic enzymes and functions [13]. Thus, the membrane-shielding effects of EPA may primarily cause the resistant mechanism of DH5 $2 \mathrm{EPA}+$ against ethanol. This is supported by the findings that an $E$. coli mar mutant deficient in multiple antibiotics resistance and an $\operatorname{acr} A B$ mutant display the same tolerance to simple alcohols as their parents [14]. 
Table 4. Effects of the EPA Content on the Cell Surface Hydrophobicity of Various E. coli DH5 $\alpha$ Recombinants Grown at 15,20 or $30^{\circ} \mathrm{C}$

\begin{tabular}{|c|c|c|c|c|c|}
\hline & \multicolumn{5}{|c|}{ E. coli DH5 $\alpha$ Carrying } \\
\hline & $\operatorname{pEPA} \Delta 1,3,4,9$ & $\begin{array}{c}\text { pEPA } \Delta 1,2,3 \\
+ \text { pSTV::pfaE }\end{array}$ & $\begin{array}{c}\operatorname{pEPA} \Delta 1,2,3 \\
+\operatorname{pSTV}:: p f a E\end{array}$ & $\begin{array}{c}\operatorname{pEPA} \Delta 1,2,3 \\
+ \text { pSTV }^{\mathrm{c}}\end{array}$ & $\begin{array}{c}\text { pEPA } \Delta 1,2,3 \\
+ \text { pSTV::pfaE }\end{array}$ \\
\hline Growth temp. ${ }^{\circ} \mathrm{C}$ & 20 & 15 & 20 & 20 & 30 \\
\hline EPA content $(\%)^{\mathrm{a}}$ & $21 \pm 2$ & $16 \pm 1$ & $11 \pm 1$ & N.D. ${ }^{d}$ & N.D. \\
\hline Hydrophobicity ${ }^{\mathrm{a}, \mathrm{b}}$ & $87 \pm 2$ & $93 \pm 5$ & $96 \pm 1$ & $98 \pm 0$ & $98 \pm 0$ \\
\hline
\end{tabular}

${ }^{a}$ Values are average \pm standard deviation of three independent measurements.

${ }^{\mathrm{b}}$ Hydrophobicity is expressed as the percentage adhesion of bacterial cells to water; lower values show higher hydrophobicity of cells.

${ }^{c} \mathrm{pEPA} \Delta 1,2,3+\mathrm{pSTV}:: p f a E$ and pEPA $\Delta 1,2,3+\mathrm{pSTV}$ are DH5 $\alpha \mathrm{EPA}+$ and DH5 $\alpha \mathrm{EPA}-$, respectively.

${ }^{\mathrm{d}}$ Not detected.

It is worth noting that there is a close relation between an improvement of organic solvent tolerance and resistance to multiple antibiotics in E. coli [15]. This is in line with the finding that the presence of EPA in E. coli confers resistance against antibiotics (Table 2) and ethanol (Table 3). It is conceivable that the common efflux pumping systems are involved in the resistance against antibiotics and organic solvents in E. coli systems including DH5 $\alpha$ EPA+.

Based on the present and previous studies [1-5, 9], it has become evident that bacterial EPA (and probably DHA) has functions other than that to modulate the membrane fluidity in the cold adaptation.

\section{CONFLICT OF INTEREST}

None declared.

\section{ACKNOWLEDGEMENTS}

pEPA $\Delta 1,2,3, \mathrm{pSTV}:: p f a E$ and pEPA $\Delta 1,3,4,9$ were kindly provided by Sagami Chemical Research Center, Ayase 2521193, Japan. This work was partly supported by the National Institute of Polar Research and by Grant-in-Aid for Scientific Research ((C) no. 22570130) from the Ministry of Education, Science, Sports, and Culture of Japan.

\section{REFERENCES}

[1] Nishida T, Yano Y, Morita N, Okuyama $H$. The antioxidative function of eicosapentaenoic acid in a marine bacterium, Shewanella marinintestina IK-1. FEBS Lett 2007; 581: 4212-6.

[2] Okuyama H, Orikasa Y, Nishida T. Significance of antioxidative function of eicosapentaenoic and docosahexaenoic acids in marine microorganisms. Appl Environ Microbiol 2008; 74: 570-4.

[3] Nishida T, Orikasa Y, Ito Y, et al. Escherichia coli engineered to produce eicosapentaenoic acid becomes resistant against oxidative damages. FEBS Lett 2006; 580: 2731-5.
[4] Nishida T, Orikasa Y, Watanabe K, Okuyama H. The cell membrane-shielding function of eicosapentaenoic acid for Escherichia coli against exogenously added hydrogen peroxide. FEBS Lett 2006; 580: 6690-4.

[5] Nishida T, Hori R, Morita N, Okuyama H. Membrane eicosapentaenoic acid is involved in the hydrophobicity of bacterial cells and affects the entry of hydrophilic and hydrophobic compounds. FEMS Microbiol Lett 2010; 306: 91-6.

[6] Rosenberg M, Gutnick D, Rosenberg E. Adherence of bacteria to hydrocarbons: a simple method for measuring cell-surface hydrophobicity. FEMS Microbiol Lett 1980; 9: 29-33.

[7] Orikasa Y, Nishida T, Hase A, et al. A phosphopantetheinyl transferase gene essential for biosynthesis of $n-3$ polyunsaturated fatty acids from Moritella marina strain MP-1. FEBS Lett 2006; 580: 4423-9.

[8] Orikasa Y, Yamada A, Yu R, et al. Characterization of the eicosapentaenoic acid biosynthesis gene cluster from Shewanella sp. strain SCRC-2738. Cell Mol Biol 2004; 50: 625-30.

[9] Nishida T, Orikasa Y, Watanabe K, et al. Evaluation of the antioxidative effects of eicosapentaenoic acid by growth inhibition testing on plates using Escherichia coli transformed with pfa genes. In: Benning C, Ohlrogge J, Eds. Current advances in the biochemistry and cell biology of plant lipids. Aardvark Global Pub. Co. Salt Lake City, UT. 2007; pp. 116-9.

[10] Ingram LO. Ethanol tolerance in bacteria. Crit Rev Biotechnol 1990; 9: 305-19.

[11] Nikaido H, Vaara M. Molecular basis of bacterial outer membrane permeability. Microbiol Rev 1990; 49: 1-32.

[12] Kawamoto J, Kurihara T, Yamamoto K, et al. Eicosapentaenoic acid plays a beneficial role in membrane organization and cell division of a cold-adapted bacterium, Shewanella livingstonensis Ac10. J Bacteriol 2009; 191: 632-40.

[13] Osman YA, Ingram LO. Mechanism of ethanol inhibition of fermentation in Zymomonas mobilis CP4. J Bacteriol 1985; 164: 173-80.

[14] Ankarloo J, Wikman S, Nicholls IA. Escherichia coli mar and acrAB mutants display no tolerance to simple alcohols. Int J Mol Sci 2010; 11: 1403-12.

[15] Aono R, Kobayashi M, Nakajima H, Kobayashi H. A close correlation between improvement of organic solvent tolerance levels and alteration of resistance toward low levels of multiple antibiotics in Escherichia coli. Biosci Biotechnol Biochem 1995; 59: 213-8. 